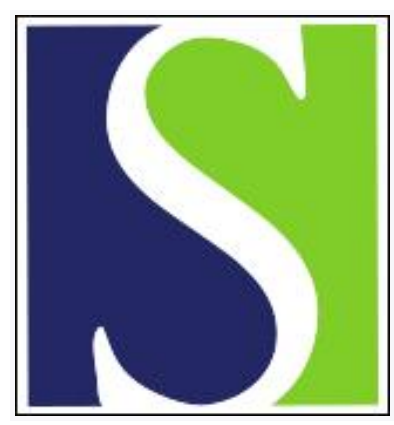

Scand J Work Environ Health 1984;10(2):75-81

https://doi.org/10.5271/sjweh.2358

Issue date: Apr 1984

Urinalysis of minor metabolites of ethylbenzene and $\mathbf{m}$-xylene. by Engstrom KM

This article in PubMed: www.ncbi.nlm.nih.gov/pubmed/6206558

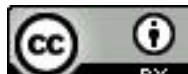




\title{
Urinalysis of minor metabolites of ethylbenzene and $\mathrm{m}$-xylene
}

\author{
by Kerstin M Engström, $\mathrm{PhL}^{\uparrow}$
}

\begin{abstract}
ENGSTRÖM KM. Urinalysis of minor metabolites of ethylbenzene and m-xylene. Scand $J$ Work Environ Health 10 (1984) 75-81. Gas chromatographic methods have been developed for the urinalysis of metabolic products of ethylbenzene. "Minor" metabolites were emphasized in this process. The methods were worked out so that simultaneous detemination of several compounds could be achieved with one method. On the whole, four assays are described, which together allow 12 different compounds to be measured. Since one of the methods presented can be applied to determine "minor" metabolites of xylene as well, methodological data for these are also reported. The methods described have successfully been used in metabolic studies of ethylbenzene in rat and man.
\end{abstract}

Key terms: acetophenone, 2,4-dimethylphenol, 4-ethylphenol, hydroxyacetophenones, 3-methylbenzylalcohol, phenylacetic acid, 1-phenyl-1,2-ethanediol, 1-phenylethanol, phenylglyoxal, phenylglyoxylic acid.

Most organic xenobiotics undergo biotransformation in living organisms and are excreted as metabolites in urine. The importance of measuring urinary metabolites has recently been summarized by Breimer (3). He emphasized the following three major reasons for carrying out such measurements: (i) to obtain pertinent information on the biotransformation of a compound in the body, (ii) to use in exposure tests (biological monitoring), and (iii) to use as a measure of the activity of metabolic pathways in the assessment of interindividual differences or in the assessment of changes caused by xenobiotics. Furthermore, the technique involved is noninvasive and, as far as, for example, biotransformation studies are concerned, is almost the only method of choice. The metabolite concentrations are mostly far higher than in plasma because of the concentrating effect in the renal tubuli. From the analytical point of view measurable amounts are a prerequisite, and many metabolites cannot even be detected in plasma.

My interest in the biotransformation of ethylbenzene led me to work out methods for identifying and measuring metabolic products of ethylbenzene in urine. The determination of two of its metabolites, mandelic and hippuric acid, which are also metabolites of styrene, has already been extensively used in earlier studies and needs no further development $(5$, $7,8)$.

The compounds under consideration, although end products of the main pathway of ethylbenzene metab-

1 Turku Regional Institute of Occupational Health, Turku, Finland.

Reprint requests to: Ms KM Engström, Turku Regional Institute of Occupational Health, Hämeenkatu 10, SF-20500 Turku, Finland. olism, may not be the most important from a toxicologic point of view. "Minor" metabolites, in a quantitative sense, should however be searched for as well, as they are often end products of metabolic pathways involving reactive intermediates. The methods developed in the present study deal particularly with "minor" metabolites.

During this work particular emphasis was put on saving time; thus special attention was paid to developing methods which allow simultaneous determination of several compounds of interest with one and the same method. Although the methods are primarily planned for assessing ethylbenzene exposure, methodological data from "minor" metabolites of m-xylene are also presented as these compounds can be detected with one of the methods presented. Furthermore ethylbenzene occurs in work conditions almost solely in connection with xylene (technical xylene contains about $15 \%$ ethylbenzene) (12). The present methods have been employed in metabolic studies of ethylbenzene in man and rat and have been shown to be very useful.

\section{Material and methods}

\section{Chemicals}

Phenylglyoxylic acid, 4-ethylphenol, m-hydroxyacetophenone, and $\mathrm{p}$-hydroxyacetophenone were obtained from Fluka, Switzerland; and 1-phenyl-1,2-ethanediol, acetophenone, 1-phenylethanol, and 2,4-dimethylphenol from Merck Schuchardt, the Federal Republic of Germany, of the highest purity available. Phenylglyoxal, $\omega$-hydroxyacetophenone, 3-methylbenzylalcohol, phenylacetylglycin and phenylacetylglutamine could not be obtained through commercial sources, 
but were kindly synthesized by Rainer Sjöholm, PhD, Department of Organic Chemistry, Ảbo Akademi, Turku, Finland. All other reagents used were of analytical-reagent grade.

\section{Urine specimens}

Specimens were obtained from volunteers exposed to ethylbenzene (150 ppm) and m-xylene (150 ppm), as well as from rats exposed to the same compounds (exposure range $25-600 \mathrm{ppm}$ ).

\section{Method 1. Determination of phenylglyoxylic acid and phenylglyoxal}

Pretreatment of sample. The keto group of phenylglyoxylic acid was blocked before silylation with 1,2-phenylenediamine according to the procedure suggested by Tejedor in a personal communication (Tejedor, JN, Servicio Social de Hygiene y Seguridad del Trabajo, Departamento de Higiene Industrial, Torrelaguna, 73, Madrid-27, Spain). One milliliter of urine and $2 \mathrm{ml}$ of a $1 \%$ solution of 1,2-phenylenediamine in $2 \mathrm{~N}$ hydrochloric acid was kept for $1 \mathrm{~h}$ in an oven $\left(70^{\circ} \mathrm{C}\right)$. The reaction mixture was thereafter cooled and saturated with sodium chloride. The reaction product of phenylglyoxylic acid was extracted with 5 $\mathrm{ml}$ of diethylether, and $1 \mathrm{ml}$ of the extract was transferred to another test tube and evaporated to dryness. Next $50 \mu \mathrm{l}$ of pyridine and $50 \mu \mathrm{l}$ of $\mathrm{N}, 0$-bis (trimethylsilyl) trifluoroacetamide (BSTFA) (Pierce Chemical $\mathrm{Co}$, the United States) were added, and the test tube was kept for $30 \mathrm{~min}$ in an oven $\left(70^{\circ} \mathrm{C}\right)$. One microliter of the solution was injected into the gas chromatograph.

Chromatographic procedure. A Hewlett Packard model $5710 \mathrm{~A}$ gas chromatograph equipped with a flame-ionization detector was used. The column was a 50-m long macrocapillary column (internal diameter $0.7 \mathrm{~mm}$ ), coated with SE-30 (Ultrasep, Finland). The temperatures were as follows: injector $250^{\circ} \mathrm{C}$, oven $230^{\circ} \mathrm{C}$, and detector $300^{\circ} \mathrm{C}$. Helium was used as the carrier gas at a flow rate of $10 \mathrm{ml} / \mathrm{min}$. The method described can successfully be used for determining phenylglyoxal as well.

\section{Method 2. Determination of phenylacetic acid}

Pretreatment of sample. Urinary excretion of phenylacetic acid usually occurs in a conjugated form, either as a glycin or glutamine complex. Prior to the analysis by gas-liquid chromatography (GLC) the conjugate must be split. The splitting was achieved by alkaline hydrolysis. One milliliter of urine and $1 \mathrm{ml}$ of $11 \mathrm{~N}$ sodium hydroxide was kept in a boiling water bath $\left(100^{\circ} \mathrm{C}\right)$ for $1 \mathrm{~h}$. The hydrolysate was thereafter acidified with $2.5 \mathrm{mI}$ of $6 \mathrm{~N}$ sulfuric acid and saturated with sodium chloride. The liberated phenylacetic acid was thereafter extracted with $5 \mathrm{ml}$ of diethylether. One milliliter of the extract was transferred to another test tube and evaporated to dryness. Prior to the GLC analysis, silylation was performed with $100 \mu \mathrm{l}$ of BSTFA in pyridine (1:1).

Chromatographic procedure. GLC analysis was carried out with the same equipment as described for method 1 . The temperatures were injector $200^{\circ} \mathrm{C}$, oven $160^{\circ} \mathrm{C}$, and detector $200^{\circ} \mathrm{C}$.

Method 3. Determination of acetophenone, 1-phenylethanol, w-hydroxyacetophenone, 4-ethylphenol, 2,4dimethylphenol and 3-methylbenzylalcohol

Pretreatment of sample. Prior to GLC analysis in method 3 some kind of hydrolysis must be performed as the monitored compounds are only partly excreted in free form. For acid hydrolysis $5 \mathrm{ml}$ of urine and $0.5 \mathrm{ml}$ of concentrated sulfuric acid was kept at $70^{\circ} \mathrm{C}$ in an oven for $18 \mathrm{~h}$. Enzymatic hydrolysis was effected by the mixing of a $5 \mathrm{ml}$ aliquot of urine with $5 \mathrm{ml}$ of phosphate buffer $(0.075 \mathrm{M})$, after which 5,600 units of bacterial $\beta$-glucuronidase (type IX, no G 3510) or 324 units of sulfatase (type H-I, no S 9626 , contains glucuronidase activity) was added. In the first case the $\mathrm{pH}$ of the phosphate buffer was 6.8, and in the latter it was 5.0. A few drops of chloroform were added to improve the enzymatic activity. This mixture was incubated for $24 \mathrm{~h}$ at $37^{\circ} \mathrm{C}$ in a water bath and acidified with $6 \mathrm{~N}$ hydrochloric acid before extraction. For extraction of the hydrolysates (enzymatic or acid) either dichloromethane or diethylether was employed. The dichloromethane extraction procedure was as follows: All the hydrolysate was shaken three times with $7 \mathrm{ml}$ of dichloromethane, the combined extracts were washed (by shaking) three times with $15 \mathrm{ml}$ of sodium bicarbonate solution $(5 \%)$, and finally the extract was dried with sodium sulfate. The dichloromethane extract was thereafter evaporated almost to dryness, and $1 \mathrm{ml}$ of dichloromethane was added immediately, from which $1 \mu \mathrm{l}$ was then injected into the gas chromatograph. Alternatively (depending on the concentration of the monitored compounds) a shorter and more simple extraction procedure can be used. It involves one-step diethylether extraction of a sodium chloride-saturated hydrolysate. The GLC analysis was in this case performed directly from the organic phase without prior washing.

Chromatographic procedure. The gas chromatograph was a Varian model 3700 with a flame-ionization detector. A 35-m fused silica capillary column (internal diameter $0.2 \mathrm{~mm}$ ) coated with methylsilicone (SP-2100) was kept for $7 \mathrm{~min}$ at $95^{\circ} \mathrm{C}$, after 
which the temperature was raised to $120^{\circ} \mathrm{C}$ at a rate of $4^{\circ} \mathrm{C} / \mathrm{min}$. The injector and detector temperatures were both $200^{\circ} \mathrm{C}$. Helium was used as the carrier gas at a flow rate of $0.4 \mathrm{ml} / \mathrm{min}$, and the split ratio was 1 to 35 . The chemical identity of the compounds was checked with another capillary column, coated with SP-1000.

Method 4. Determination of m-hydroxyacetophenone, p-hydroxyacetophenone and 1-phenyl-1,2-ethanediol

Pretreatment of sample. Enzymatic hydrolysis according to method 3 was used. The hydrolysate was thereafter acidified with $6 \mathrm{~N}$ hydrochloric acid, saturated with sodium chloride, and extracted with diethylether. One milliliter of the extract was transferred to another test tube and evaporated to dryness. Next $50 \mu \mathrm{l}$ of pyridine and $50 \mu \mathrm{l}$ of BSTFA were added for the GLC analysis.

Chromatographic procedure. The same equipment as described for method 3 was employed. The SP-2100 column was kept at $130^{\circ} \mathrm{C}$.

\section{Quantification}

Integration of the chromatographic peaks were, for all methods, performed with the Perkin-Elmer Data Station, model Sigma 10. For methods 1 and 2 internal calibration was usually employed, whereas for the rest of the compounds external standards were used.

\section{Identification}

The compounds were identified through a comparison of the retention times, as well as mass spectral data, with those of reference compounds. Mass spectral data also confirmed the selectivity of the chromatographic peaks. This procedure was performed with an LKB-9000 instrument, which was equipped with a column similar to that already described in the respective method. The temperature of the ion source was $290^{\circ} \mathrm{C}$.

\section{Statistical methods}

The precision of the analysis was defined from the calculation of the coefficient of variation $(\mathrm{CV}=$ $\mathrm{SD} /$ mean) between replicate analyses in the same run denoted "within-series" variation. Imprecision between different runs, "day-to-day" variation, was determined for the procedure described in method 3 . This variation was calculated from a calibrating curve combined from four different runs (range 3 to $1,000 \mu \mathrm{mol} / \mathrm{l}, \mathrm{N}=24$ ). Variation of the curve (defined as $2 \sigma$ ) was given for the same concentration as was used for the "within-series" variation.

\section{Results and discussion}

\section{Method I}

It is well known that there are difficulties involved in the determination of phenylglyoxylic acid (6). These difficulties are connected to its $\alpha$-keto acid character, which influences the reproducibility of the derivatization step in an undesirable way. The problem was solved by the use of protective derivatization with 1,2-phenylendiamine of the keto group, before the silylation of the residual acid group. Phenylglyoxal, having two adjacent keto groups, also reacts easily with 1,2-phenylendiamine and can thus successfully be determined by the same procedure. This phenomenon is valuable since phenylglyoxal, being a precursor to phenylglyoxylic acid, may also, to a small extent, be excreted in the urine. The reaction procedures of both compounds were verified by mass spectal analysis. Mass spectral data on the final derivatization products (after silylation) were as follows: phenylglyoxylic acid [ionization potential $70 \mathrm{eV} ; \mathrm{m} / \mathrm{e}$ (\%) relative intensity)]: $294(47.5, \mathrm{M}), 279(100.0), 217$ $(35.0), 132(23.0), 102(8.5), 90(9.7)$; and phenylglyoxal [ionization potential $70 \mathrm{eV} ; \mathrm{m} / \mathrm{e}(\%$ relative intensity)]: $206(100.0, \mathrm{M}), 179(40.0), 178(12.0), 103$ (18.0), $76(32.0), 50(18.0)$. According to these data, phenylquinoxalone is the reaction product of $1,2-$ phenylendiamine and phenylglyoxal, which means that all active groups of phenylglyoxal are inactivated already during the first reaction step. Thus no further derivatization is necessary if only this compound is of interest.

The reproducibility of 10 replicate added samples was $6.4 \%$ for $1 \mathrm{mmol}$ of phenylglyoxylic acid/1 of urine and $9.5 \%$ for $0.5 \mathrm{mmol}$ of phenylglyoxal $/ \mathrm{l}$ of urine.

\section{Method 2}

Phenylacetic acid is excreted primarily unchanged and as phenylacetylglutamine by primates, though it is excreted in the form of glycin conjugate by rodents (10). In an earlier study (9) phenylacetyltaurine was reported as a minor metabolite of phenylacetic acid in man, as well as in the Wistar rat. This observation could not however be repeated by Jones (10). He, on the other hand, found that also rats, after the administration of phenylacetic acid, excrete it partly $(10 \%)$ in the form of glutamine conjugate.

When the total excretion of phenylacetic acid in urine is being measured, it must be kept in mind that two types of conjugate, as well as excretion in free form, are possible. This fact has been considered in the present method, in which the conjugates are split prior to the GLC analysis, and thus the result obtained represents the sum of both free and conjugated acid.

The recovery test showed that the conjugates could be hydrolyzed almost completely by the alkaline treatment. The recovery of phenylacetylglycin was 
Table 1. Influence of incubation time on the yield of added 1-phenylethanol and acetophenone (determined by acid hydrolysis one-step diethylether extraction, and gas-liquid chromatography) in water and urine.

\begin{tabular}{|c|c|c|c|c|c|}
\hline \multirow{3}{*}{$\begin{array}{c}\text { Incubation } \\
\text { time } \\
\text { (h) }\end{array}$} & \multirow{3}{*}{$\begin{array}{c}\text { Amount } \\
\text { added } \\
(\mathrm{mmol} / /)\end{array}$} & \multicolumn{4}{|c|}{ Recovery (\%) } \\
\hline & & \multicolumn{2}{|c|}{ 1-Phenylethanol } & \multicolumn{2}{|c|}{ Acetophenone } \\
\hline & & Water & Urine & Water & Urine \\
\hline 0.5 & $\begin{array}{l}3.0 \\
5.0\end{array}$ & $\begin{array}{r}96 \\
102\end{array}$ & $\begin{array}{r}95 \\
100\end{array}$ & $\begin{array}{r}98 \\
101\end{array}$ & $\begin{array}{r}99 \\
103\end{array}$ \\
\hline 1.0 & $\begin{array}{l}3.0 \\
5.0\end{array}$ & $\begin{array}{r}93 \\
102\end{array}$ & $\begin{array}{r}70 \\
101\end{array}$ & $\begin{array}{l}101 \\
103\end{array}$ & $\begin{array}{r}94 \\
103\end{array}$ \\
\hline 3.0 & $\begin{array}{l}3.0 \\
5.0\end{array}$ & $\begin{array}{l}95 \\
97\end{array}$ & $\begin{array}{l}79 \\
85\end{array}$ & $\begin{array}{l}101 \\
100\end{array}$ & $\begin{array}{l}102 \\
111\end{array}$ \\
\hline 18.0 & $\begin{array}{l}3.0 \\
5.0\end{array}$ & $\begin{array}{l}75 \\
76\end{array}$ & $\begin{array}{l}28 \\
30\end{array}$ & $\begin{array}{l}95 \\
98\end{array}$ & $\begin{array}{l}102 \\
101\end{array}$ \\
\hline
\end{tabular}

Table 2. Comparison of 1-phenylethanol determined in rat urine by enzymatic and acid hydrolysis.

\begin{tabular}{lccc}
\hline & \multicolumn{3}{c}{ Concentration (mmol/l) } \\
\cline { 2 - 4 } Sample & $\begin{array}{c}\text { Enzymatic } \\
\text { hydrolysis }\end{array}$ & \multicolumn{2}{c}{ Acid hydrolysis } \\
\cline { 3 - 4 } & & $0.5-h$ incubation & 18-h incubation \\
\hline 1 & 1.8 & 1.7 & 2.5 \\
2 & 3.4 & 4.2 & 2.4 \\
3 & 4.1 & 4.2 & 4.2 \\
4 & 6.4 & 7.1 & 3.8 \\
\hline
\end{tabular}

$100 \%$, and that of phenylacetylglutamine $83 \%$. The reproducibility of the method was good. The coefficient of variation was $3 \%$ for an added sample (concentration $5 \mathrm{mmol} / \mathrm{l}, \mathrm{N}=10$ ).

\section{Method 3}

Hydrolysis. Alcoholic and phenolic metabolites formed from aromatic hydrocarbons in the body are excreted in the form of some conjugate. For the final GLC analysis the compounds must however again be in free form. For this purpose both acid and enzymatic hydrolysis has been used $(1,2,11,13)$. Both methods were also tested in the present study, in which the enzymatic version was shown to be preferable. For the acid hydrolysis the procedure employed by Pfäffli et al (13) for the determination of o-cresol was tested. However, in the case of 1-phenylethanol, it did not fulfill the requirements for reproducibility and linearity. During the acid incubation some unexpected destruction of added 1-phenylethanol in the urine occurred. This unknown phenomenon could also be seen in water solutions of 1-phenylethanol, though to a less remarkable extent (table 1). According to table 1 the change seems not to be especially concentration dependent. Anyhow, similar tests with a much smaller concentration $(0.25 \mathrm{mmol} / \mathrm{l}$ of urine) showed even a 1 -h incubation to cause a loss of $30 \%$ and the loss with a 5 -h incubation to be $65 \%$. None of the other tested compounds showed similar changes, as shown by the results of acetophenone presented in table 1 . Further investigations of urine samples from exposed rats showed that the 1-phenylethanol concentrations obtained with the acid treatment varied from 60 to $140 \%$ in comparison with corresponding values obtained by enzymatic hydrolysis (table 2). This discrepancy was apparently due to the instability of standards (samples) used in the acid method. It is furthermore impossible to believe that the undesirable secondary reaction proceeds at the same rate in standards and samples, since 1-phenylethanol exists in the standard in free form right from the beginning, whereas in the sample its conjugates must be hydrolyzed first. This disagreement seemed to be less pronounced with the shorter incubation time $(0.5 \mathrm{~h})$ (table 2).

It was however shown for the other compounds which can be analyzed with this method that the acid hydrolysis time needs to be far longer, preferably overnight. Thus, since the safety margin for finding a suitable time for the acid hydrolysis seemed to be too narrow, the only possibility of choice for the hydrolysis appeared to be the enzymatic procedure. As regards the other monitored compounds, the success of the respective hydrolysis procedure should, in every case, be expressly investigated. Thus, generally, the enzymatic hydrolysis is to be recommended, except for 2,4-dimethylphenol, for which markedly higher results were obtained with the acid assay.

Extraction. The monitored compounds must be isolated from the urine before the chromatographic step can be performed. For this purpose dichloromethane and diethylether proved to be suitable solvents. Diethylether extraction (one-step, without washing) was shown to be fully sufficient, if the concentrations to be analyzed exceed $20 \mu \mathrm{mol} / 1$. Otherwise, the more time-consuming dichloromethane extraction procedure, including a concentration step (by evaporation), must be used. It is however not only the concentrating effect, but also the sodium bicarbonate washing step included in this extraction procedure, that makes this assay more advantageous. The purpose of the washing is, namely, to remove acids from the nonaqueous phase, which again is aimed at reducing the interference of the chromatography of the monitored compounds. The differences in the two 


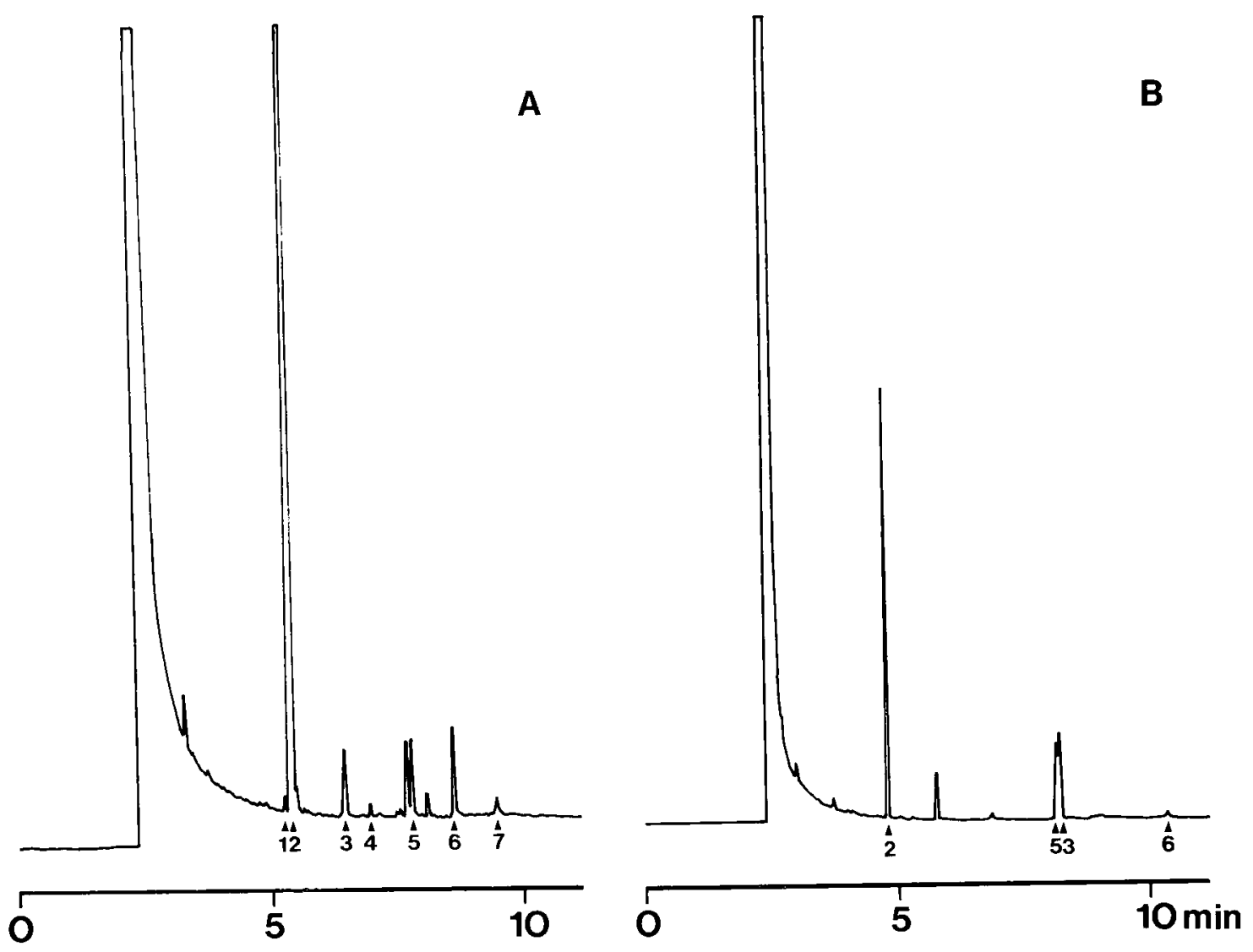

Figure 1. Gas chromatograms of two different extracts (A, B) of a hydrolyzed human urine sample following exposure to a mixture of ethylbenzene and $\mathrm{m}$-xylene $(150 / 150 \mathrm{ppm})$. The peaks were identified and measured as follows: $1=$ acetophenone $(3$ $\mu$ mol/i), $2=1$-phenylethanol $(900 \mu \mathrm{mol} / \mathrm{l}), 3=$-cresol (normal constituent), $4=3$-methylbenzylalcohol $(4 \mu \mathrm{mol} / \mathrm{l}), 5=$ $\mu$ mol/i), 2 -dimethylphenol $(20 \mu \mathrm{mol} / /), 6=4$-ethylphenol $(17 \mu \mathrm{mol} / / \mathrm{l})$, and $7=\omega$-hydroxyacetophenone $(8 \mu$ mol/ll). Chromatogram A cor2,4 -dimethylphenol $(20 \mu \mathrm{mol} / \mathrm{)}, 6=4$-ethylphenol $(17 \mu \mathrm{mo} / \mathrm{h})$, and $7=\omega$-hydroxyacetophen column of fused silica coated with responds to the dichloromethane extraction procedure and separation on a capillary column of fused silica coated with
SP-2100. Chromatogram B corresponds to the diethylether extraction procedure and separation on a capillary column coated with SP-1000.

Table 3. Recovery of the compounds monitored with method 3. (ND $=$ not determined)

\begin{tabular}{|c|c|c|c|}
\hline \multirow[b]{2}{*}{ Compound } & \multirow{2}{*}{$\begin{array}{c}\text { Amount } \\
\text { added } \\
(\mu \mathrm{mol} / \mathrm{l})\end{array}$} & \multicolumn{2}{|c|}{ Recovery } \\
\hline & & $\begin{array}{l}\text { Dichloromethane } \\
\text { extraction }(\%)\end{array}$ & $\begin{array}{c}\text { Diethyleter } \\
\text { extraction (\%) }\end{array}$ \\
\hline $\begin{array}{l}\text { Acetophenone } \\
\text { 1-Phenylethanol } \\
\text { 3-Methylbenzylalcohol } \\
\text { 2,4-Dimethylphenol } \\
\text { 4-Ethylphenol } \\
\omega \text {-Hydroxyacetophenone }\end{array}$ & $\begin{array}{r}100 \\
1,000 \\
100 \\
100 \\
100 \\
100\end{array}$ & $\begin{array}{l}80 \\
84 \\
86 \\
84 \\
86 \\
63\end{array}$ & $\begin{array}{l}96 \\
99 \\
\text { ND } \\
\text { ND } \\
\text { ND } \\
84\end{array}$ \\
\hline
\end{tabular}

extraction procedures are shown by the chromatograms presented in figure 1 . The recovery for different extraction procedures is presented in table 3 . The divergence of about $15 \%$ which exists between the two extraction assays cannot be explained by a corresponding difference in the extraction efficiency of the two solvents. The analytes, being more or less water soluble, are, rather, supposed to pass partly back to the aqueous layer and result in an incomplete extraction yield. Since the yield was reproducible, the dichloromethane extraction procedure was considered to be fully sufficient also for quantitative determination. Incidentally, a good linearity was also obtained throughout the working range, a finding which indicates that no concentration dependence existed. Adjustment for incomplete recovery was achieved by the procedure of subjecting the standards to exactly the same treatment as the samples, equal 
Table 4. Reproducibility of the compounds monitored with method 3.

\begin{tabular}{|c|c|c|c|c|}
\hline \multirow{2}{*}{ Compound } & \multirow{2}{*}{$\begin{array}{l}\text { Amount added } \\
(\mu \mathrm{mol} / \mathrm{l})\end{array}$} & \multicolumn{3}{|c|}{ Coefficient of variation } \\
\hline & & $\begin{array}{c}\text { Day-to-day } \\
(\%)\end{array}$ & $\begin{array}{c}\text { Within-series } \\
(\%)\end{array}$ & $\begin{array}{c}\text { Chromatographic } \\
(\%)\end{array}$ \\
\hline $\begin{array}{l}\text { Acetophenone } \\
\text { 1-Phenylethanol } \\
\text { 3-Methylbenzylalcohol } \\
\text { 2,4-Dimethylphenol } \\
\text { 4-Ethylphenol } \\
\text { w-Hydroxyacetophenone }\end{array}$ & $\begin{array}{r}100 \\
1,000 \\
100 \\
100 \\
100 \\
100\end{array}$ & $\begin{array}{r}16.2 \\
9.2 \\
13.4 \\
15.1 \\
15.2 \\
13.3\end{array}$ & $\begin{array}{r}6.2 \\
5.3 \\
5.9 \\
6.4 \\
7.3 \\
11.9\end{array}$ & $\begin{array}{l}5.3 \\
6.2 \\
5.3 \\
5.0 \\
4.2 \\
5.2\end{array}$ \\
\hline
\end{tabular}

a Six injections of the same pretreated sample.

Table 5. Recovery and reproducibility of 10 added samples (2 $\mathrm{mmol} / \mathrm{l})$ in method 4.

\begin{tabular}{lcc}
\hline Compound & $\begin{array}{c}\text { Recovery } \\
(\%)\end{array}$ & $\begin{array}{c}\text { Reproducibility } \\
(\%)\end{array}$ \\
\hline m-Hydroxyacetophenone & 99 & 3.6 \\
1-Phenyl-1,2-ethanediol & 68 & 4.6 \\
p-Hydroxyacetophenone & 100 & 4.6 \\
\hline
\end{tabular}

recovery for both being the result. Furthermore, when the determination of 1-phenylethanol was performed on a set of samples by both extraction procedures, no difference in the results could be seen.

Chromatographic separation. Good separation was achieved with both columns (figure 1). The reliability of the identification could however be improved by the use of two different columns. An overlapping of 2-phenylethanol and 2,6-dimethylphenol was observed, but, since these compounds were of minor importance in the metabolic studies, no further attempt to eliminate this discrepancy was made. On the SP-1000 column, p-cresol moves into the vicinity of 2,4-dimethylphenol and may thus influence the accuracy of its determination. For the same reason eugenol (occasionally occurring in the urine of nonexposed persons) interferes with the determination of 4-ethylphenol.

Reproducibility of the results. The reproducibility of the method was tested with six repeated analyses of an added urine sample (table 4). "Day-to-day" variation was also determined as the time-demand (only six analyses can be handled in a normal workday) of the method makes calibration every day inconceivable. These values are naturally more prone to variability than the corresponding "within series" values, which principally seem to be dependent on chromatographic variation (table 4).

\section{Method 4}

For the isolation of 1-phenyl-1,2-ethanediol and hydroxyacetophenones both dichloromethane (com- bined with sodium bicarbonate washing) and diethylether extraction were tested, the results proving diethylether to be a good extraction solvent for $\mathrm{m}$ and p-hydroxyacetophenone, according to their recovery data (table 5). The incomplete recovery of 1-phenyl-1,2-ethanediol showed such good reproducibility (table 5) that it was considered justified to compensate for the loss by subjecting standards to the same treatment as samples. The back-extraction procedure resulted in such a poor recovery (about $10 \%$ ) that it could not be applied in this method. Its exclusion caused some problems during the chromatography of the compounds, however, as aromatic phenolic acids could not be removed from the organic phase prior to derivatization. The silylated acids proved to have much longer retention times, however, than the monitored compounds under the given chromatographic conditions. These circumstances caused, especially in serial investigations, minor complications, as late eluting compounds have a tendency to raise the background level and thus interfere with the quantification of monitored compounds. The problem can be overcome with an increase in the column temperature before the beginning of the next analysis. My intention originally was to apply the system described in method 3 also for the determination of the compounds determined by method 4 . It appeared however that, in addition to the drawback of the washing procedure, the compounds, when underivatized, proved to have impractically long retention times.

\section{Applicability of the methods}

The present methods enable a reliable determination of minor metabolites of ethylbenzene and xylene in the urine. Many of the compounds presented may not be suitable for biological monitoring, but the methods are anyhow indispensable for the study of total disposition (including biotransformation and kinetics of a compound in the body), which again is of utmost importance for the development of useful exposure tests. In the methods of this paper, the main emphasis is put on "minor" metabolites. The first two 
methods can however be applied to determine the main metabolites of ethylbenzene and xylene as well. Thus method 1 allows simultaneous determination of mandelic acid, whereas the system described in method 2 has for many years been used in our laboratory for the routine determination of both hippuric and methylhippuric acid in urine. In the latter case not even the duration of analysis will be prolonged, as phenylacetic acid is eluted in order before methylbenzoic acid, but after benzoic acid. Cinnamic acid, which is used routinely as an internal standard for mandelic acid, can be applied for the internal calibration of phenylglyoxylic acid and phenylglyoxal as well. The internal standard of methylhippuric acid, 2,3-dimethylbenzoic acid, can equally be used for the purpose of internal calibration in method 2.

The range of the described methods was set to cover concentrations of the monitored compounds that could occur in the urine of persons exposed to ethylbenzene (xylene). Phenylglyoxal was an exception, as it could be measured only in rat urine after ethylbenzene exposure so heavy ( $300 \mathrm{ppm}$ ) that it can hardly be supposed to occur in work situations. Analyses of the urine of controls (ie, nonexposed persons and rats) have demonstrated that only a few of the analytes mentioned are normal urinary constituents. The only serious drawback in this respect seems to be caused by phenylacetic acid, which, in the body, is formed from phenylalanine (14). The base level of phenylacetic acid, at least in human urine, is so high and variable that reliable assessment of exposure is questionable. In scientific tables (15) the normal excretion is reported to be $1-2 \mathrm{mmol} / 24 \mathrm{~h}$, measured as phenylacetylglutamine. In nonexposed rats the phenylacetic acid excretion was determined to be 53 (SD 17) $\mu \mathrm{mol} \cdot 24 \mathrm{~h}^{-1} \cdot \mathrm{kg}^{-1}$ (range 29-92 $\mu \mathrm{mol}$. $24 \mathrm{~h}^{-1} \cdot \mathrm{kg}^{-1}, \mathrm{~N}=15$ ) (this study). Small amounts of $\mathrm{m}$-hydroxyacetophenone were also found in the urine of nonexposed persons, whereas traces of the pisomer were identified in the urine of control rats. The measured concentrations were however so low that the interference with exposure assessment was considered negligible. In the urine of control rats, 4-ethylphenol was also found to be a normal constituent, as already reported by Bakke $\&$ Scheline in an earlier study (2).

Metabolic studies of ethylbenzene are now under way in which the present methods have proved to be very useful. These investigations are being performed on both rat and man, and some of the results from the inhalation studies on rats are presented as a separate paper in this journal (4).

\section{Acknowledgment}

The author is greatly indebted to Ms E Korolainen for her skillful technical assistance.

\section{References}

1. Angerer J. Chronische Lösungsmittelbelastung am Arbeitsplatz: V Chromatographische methoden zur Bestimmung von Phenolen im Harn. Int Arch Occup Environ Health 42 (1979) 257-268.

2. Bakke OM, Scheline RR. Hydroxylation of aromatic hydrocarbons. Toxicol Appl Pharmacol 16 (1970) $691-700$.

3. Breimer DD. Measurement of urinary metabolites of xenobiotics as a noninvasive technique in toxicology. Arch Toxicol (1982): suppl 5, 162-178.

4. Engström K. Metabolism of inhaled ethylbenzene in rats. Scand J Work Environ Health 10 (1984) 83-87.

5. Engström $K$, Härkönen $H$, Pekari $K$, Rantanen $J$. Evaluation of occupational styrene exposure by ambient air and urine analysis. Scand $J$ work Environ Health 4 (1978): suppl 2, 121-123.

6. Guillemin M, Bauer D. Human exposure to styrene: II Quantitative and specific gas chromatographic analysis of urinary mandelic and phenylglyoxylic acid as an index of styrene exposure. Int Arch Occup Environ Health 35 (1976) 57-64.

7. Guillemin M, Bauer D. Biological monitoring of exposure to styrene by analysis of combined urinary mandelic and phenylglyoxylic acids. Am Ind Hyg Assoc J 39 (1978) 873-879.

8. Ikeda M, Hirayama T. Possible metabolic interaction of styrene with organic solvents. Scand J Work Environ Health 4 (1978): suppl 2, 41-46.

9. James MO, Smith RL, Williams RT, Reidenberg M. The conjugation of phenylacetic acid in man, subhuman primates and some non primate species. Proc $\mathrm{R}$ Soc London Ser B 182 (1972) 25-35.

10. Jones AR. Some observations on the urinary excretion of glycine conjugates by laboratory animals. Xenobiotica 12 (1982) $387-395$.

11. Kiese M, Lenk W. Hydroxyacetophenones: Urinary metabolites of ethylbenzene and acetophenone in the rabbit. Xenobiotica 4 (1974) 337-343.

12. National Institute for Occupational Safety and Health. Criteria for a recommended standard: Occupational exposure to xylene. US Department of Health Education and Welfare, US Government Printing Office, Washingion, DC 1975, p 14.

13. Pfäffli P, Savolainen H, Kalliomäki P-L, Kalliokoski $P$. Urinary o-cresol in toluene exposure. Scand J Work Environ Health 5 (1979) 286-289.

14. Suemitsu R, Fujita S, Yoshimura M, Soda Y. Studies on the components of mammalian urine: VI A proof of the metabolic pathway according to permanganate oxidation of ethylbenzene. Sci Eng Rev Doshisha Univ 10 (1969) $177-181$.

15. Documenta Geigy: Scientific tables. Seventh edition. Ciba-Geigy, Basle 1973, p 666.

Received for publication: 10 August 1983 